\title{
Causas de la crisis financiera en el caso español
}

\author{
Óscar Vara \\ Universidad Autónoma de Madrid
}

\section{INTRODUCCIÓN}

La recesión económica en la que se está sumiendo la economía mundial y, al mismo tiempo, la española, es el resultado de una concatenación de circunstancias que no sólo la favorecían, sino que eran generadoras de la misma. En los últimos meses, se transmiten a los medios de comunicación juicios diversos sobre las soluciones a corto plazo que serían deseables y, también, cuáles serían las medidas a medio y largo plazo que sería conveniente instrumentar a fin de evitar que se repita este tipo de crisis o, por lo menos, que se repita con la intensidad de la actual. Todas ellas están referidas a los aspectos financieros que subyacen a la crisis pero, sin embargo, parece que en estos análisis se evita con cierto cuidado advertir a la opinión pública acerca de la repetición periódica de este tipo de crisis, así como de la gravedad que han tenido en aquellos territorios donde se han producido. En esta omisión, se descubre la ausencia de una crítica de fondo y esencial a la propia constitución del sistema financiero y a su natural propensión a favorecer y provocar estas recesiones.

En nuestra opinión, las crisis financieras se producen cuando coinciden en el tiempo determinadas condiciones de posibilidad que podríamos resumir en las siguientes:

- existencia de un sistema financiero de dinero fiduciario y reserva fraccionaria;

- crecimiento elevado de la capacidad de endeudamiento a corto plazo del sistema financiero y reducción de los tipos de interés.

- aparición de una demanda creciente en algún sector económico capaz de producir un efecto de arrastre en la actividad económica global de un país (por sus cualidades específicas, por su aportación a la eficiencia productiva, por las expectativas de desarrollo que genera, etc.); 
El sistema financiero actual, gracias al sistema de reserva fraccionaria, posee una gran elasticidad de creación de medios de pago en presencia de una actividad económica creciente. De hecho, cuanto mayor sea la capacidad de endeudamiento del sector bancario, mayor es esta elasticidad y mayor la capacidad de alimentar el crecimiento económico. Sin embargo, y como muy bien han advertido diversos economistas a lo largo del siglo $\mathrm{xx}$, este crecimiento se basa en una premisa falsa: en la reducción artificialmente producida por las posibilidades de endeudamiento que crean, conjunta y retroalimentadamente, el dinero bancario y la expansión económica debida a él. Bajo estas circunstancias, que suelen depender de la coyuntura histórica concreta, el auge económico es especialmente frágil y quebradizo, tanto que, al paso del tiempo, acabará por no poder soportar la estructura de deuda a corto plazo sobre la que se sustenta, dando lugar a una caída repentina y brusca del crédito bancario y de la actividad económica..

\section{PRIMERA CONDICIÓN DE POSIBILIDAD: LA RESERVA FRACCIONARIA}

Uno de los elementos, que a nuestro juicio, constituyen la primera y fundamental de las condiciones de posibilidad de las crisis financieras como la actual, es la existencia de un sistema de reserva fraccionaria para la banca comercial. Resulta sorprendente como esta práctica, que en el pasado estuvo sometida a importantes discusiones y controversias dentro del terreno de la jurisprudencia y de la teoría económica, ha sido aceptada en nuestros tiempos como un hecho incontrovertible. De tal manera que, en el análisis de la crisis económica que se está produciendo a nivel mundial, se hurta al debate con gran facilidad, el juicio acerca de cuál es la responsabilidad de esta práctica dentro de la misma.

Como se ha demostrado en la obra de Jesús Huerta de Soto ${ }^{1}$, el moderno contrato de depósito se basa en la unión, insuficientemente declarada en la ley, de los contratos de depósito irregular (o de guarda y custodia) y el contrato de préstamo. Es decir, lo que en origen para los depositantes debería ser un contrato de guarda y custodia del dinero que depositan en el banco comercial, se convierte en una cesión implícita de la disponibilidad de dicho dinero. De esta manera, y en apariencia, el banco comercial actúa como intermediario financiero, pues la reserva fraccionaria faculta a los bancos para disponer de aquellos depósitos monetarios de corto plazo que les hacen sus clientes con el obje-

${ }^{1}$ Huerta de Soto (1998)especialmente el capítulo tercero. 
tivo de poder prestarlos a un plazo más largo (obteniendo de este arbitraje de tipos de interés un beneficio económico) ${ }^{2}$.

Sin embargo, esta actuación en apariencia de intermediario financiero de la banca comercial, se ve contradicha por la evidencia de que el dinero que ha sido depositado bajo la condición expresa de estar permanentemente a disposición del depositante, deja de estar en él una vez que ha sido prestado por el banco comercial. Por lo tanto, esta operación produce en la práctica una doble disponibilidad de los mismos recursos, para el depositante y para el depositario, que puede plantear situaciones muy problemáticas si se dan las suficientes circunstancias desfavorables.

Se produce aquí una paradoja sobre la que se edifica la fragilidad de los bancos comerciales, pues de forma permanente actúan disponiendo de un activo circulante que es crónicamente inferior a su pasivo circulante. Es decir, actúan de forma permanente con un fondo de maniobra negativo. La explicación de este fenómeno es relativamente sencilla y se basa en lo que solemos denominar creación de dinero bancario, cuyo mecanismo aprende bien pronto cualquier alumno de introducción a la economía ${ }^{3}$. Una explicación sucinta de este problema sería la siguiente: las cantidades monetarias que una persona deposita en un banco comercial constituyen una deuda a corto plazo que este banco adquiere con el depositante de tal manera que, si a continuación, ese mismo banco comercial presta parte de dichas cantidades depositadas, por ejemplo, en un préstamo hipotecario a largo plazo (en este caso, la diferencia de plazo, sería obviamente más notable, pero la situación sería la misma si estuviéramos contemplando un préstamo al consumo pues seguiría existiendo una diferencia de plazos del depósito), se convierten en un derecho de cobro a largo plazo. Por lo tanto dentro del balance contable del banco, los depósitos aparecerían como pasivo circulante mientras que los préstamos aparecerían como capital permanente exigible a largo plazo, lo que explicaría la existencia del fondo de maniobra negativo.

En cualquier caso, la realidad constatable de que no existen suficientes recursos líquidos dentro de cualquier banco comercial para hacer frente a una eventual retirada de las obligaciones a corto plazo de los mismos, explica la necesidad de mantener «un

${ }^{2}$ Aunque, y como comentaremos un poco más adelante, este tipo de negocio bancario esté dejando de ser la fuente principal de beneficios de la banca comercial, sigue siendo el elemento sobre el cual se sostiene y se edifica una estructura de deuda mayor gracias a la creatividad e inventiva de los especialistas financieros.

3 Por ejemplo en manuales como Samuelson y Nordhaus Economía, 14. a edición, McGrawHill, Madrid 1993, págs. 616-617. 
ojo siempre atento» a las actividades de los bancos comerciales, como bien reconocen las legislaciones correspondientes de cualquier país. No obstante estas precauciones, la posibilidad de que suceda un evento catastrófico que sitúe a la banca comercial en situación de iliquidez, no es descartable, como estamos experimentado en la actualidad.

\section{EXCURSO: TEORÍA ECONÓMICA Y CRÍTICA DE LA RESERVA FRACCIONARIA}

Los economistas no siempre han visto el peligro que implica esta realidad de facto del sistema financiero, pero no se puede decir que la teoría económica lo haya pasado por alto. En el siglo xx fue, sin ninguna duda, Ludwig von Mises quien con más énfasis y autoridad criticó la existencia de la reserva fraccionaria. En su aproximación al problema, entendía que la existencia de un único emisor de dinero fiduciario y la capacidad de creación de dinero bancario, podrían variar de manera artificial los tipos de interés produciendo una alteración de las señales que siguen los agentes económicos en los mercados. De aquí se derivaría una confusión sobre las posibilidades reales de obtener un beneficio económico de la expansión crediticia pues, a medio plazo o largo plazo, las inversiones iniciadas no serían rentables al no basarse en el ahorro, sino en la deuda bancaria. Es el proceso que conocemos como «ahorro forzoso» ${ }^{4}$. Esta teoría se basaba,

4 «Imaginémonos que la cantidad total de dinero gastado en bienes y servicios es absolutamente la misma 'día' tras 'día' y que el grado de integración financiera (el número de manos o de cuentas por las cuales tiene que pasar el dinero en su camino desde quien desembolsa los ingresos hasta quien recibe ingresos) tampoco cambia. En tales circunstancias, los desembolsos totales en inversión pueden aumentar, y sólo pueden aumentar, si quienes se deshacen de ingresos han decidido aumentar sus ahorros a partir de sus ingresos monetarios dados. La condición de la corriente de ingresos absolutamente constante implica una igualdad entre el ahorro y la inversión, una igualdad en la que el ahorro es la variable 'autónoma' y la inversión es la 'ajustada.' Pues, por una parte, no existen fondos asignables a las inversiones, salvo los constituidos por los dineros de los que ahorran; y, por otra parte, todos estos fondos disponibles se usan realmente en inversión, pues de lo contrario la corriente o flujo de ingresos no se mantendría constante. Si ahora, contrariamente a las condiciones descritas, se monta un aumento en la corriente de dinero y de ingresos - ya sea mediante la creación y desembolso de dinero nuevo o a través de la activación de dinero ocioso - los desembolsos en inversión ya no están limitados por las decisiones antecedentes de ahorrar tomadas por quienes reciben ingresos. La inversión puede ahora rebasar el ahorro propuesto; es decir, la formación de capital puede rebasar lo que las personas ahorraron de su ingreso 
en buena medida, en la teoría del capital de Eugene Böhm-Bawerk, perfeccionada por Knut Wicksell en sus Lecciones de Economía Política.

Por tanto, el mal del proceso se produce en su origen, cuando la demanda de inversión puede dispararse gracias a la enorme elasticidad que tiene el crecimiento de la cantidad de dinero bancario, que pone en manos de los empresarios cantidades enormes de poder de compra que se basan, en realidad, en deudas, es decir, en promesas de pago. Cuando las inversiones demuestran que no van a retornar un beneficio suficiente y la posibilidad de devolver la deuda se ve comprometida, los bancos contraen el crédito en un intento de no agravar la situación de sus pasivos. Sin embargo, este no es el origen de la crisis, sino, en cierto modo, la culminación del proceso de ahorro forzoso. Por ello, Mises afirmaba en su trabajo «The Suitability of Methods of Ascertaining Changes in the Purchasing Power for the Guidance of International Currency and Banking Policy», memorandum presentado en 1930 ante el Comité Financiero de la Liga de Naciones, y a la luz del crash de 1929, que: «the root cause of the evil is not in the restrictions, but in the expansion which preceded them. The policy of the banks does not deserve criticism for having at last called a halt to the expansion of credit, but, rather, for ever having allowed it to begin.» 5

No fueron, sin embargo, los autores de la denominada escuela austriaca de economía, los únicos en advertir del peligro de la reserva fraccionaria. Dentro del «mainstream», aparecen también voces que advierten sobre sus riesgos ${ }^{6}$. Es famoso el panfleto anónimo publicado en 1933 y que fue elaborado por autores principales de la escuela de Chicago como Henry C. Simons, Lloyd W. Mints, Aaron Director, Frank H. Knight, Henry Schultz, Paul H. Douglas, Albert G. Hart, entre otros. En esta tradición insistieron autores como Irving Fisher en su obra 100 Percent Money, e incluso el mismísimo Milton Friedman con su trabajo Un programa de estabilidad monetaria y reforma bancaria. Más recientemente, ha sido el premio Nobel de Economía Maurice Allais, el más combativo contra el sistema de reserva fraccionaria. Así, en el año 1984 advertía:

«The system generates economic imbalance, an unhealthy concentration of financial rewards, and unbridled speculation. The societies in which it is used or tolerated stagger from one crisis to the next. All the major crises of the eighteenth, nineteenth

previo; la formación de capital extra es 'forzada', impuesta, por así decirlo, a la comunidad a través de la magia monetaria." (Machlup, 1967, págs. 218-19).

5 Ebeling (1990), págs. 90-91.

${ }^{6}$ Ronnie J. Phillips, The Chicago Plan \& New Deal Banking Reform, M.E. Sharpe, Armouk, Nueva York 1995, págs. 191-198. 
and twentieth century were the result of the proliferation of promises to pay and their monetization.

It is no exaggeration to say that the present system of creating money through credit is a cancer irremediably gnawing away at the capitalist economies.» ${ }^{7}$

\section{SEGUNDA CONDICIÓN DE POSIBILIDAD: EL SECTOR INMOBILIARIO}

Casi todos los fenómenos económicos importantes, son el resultado de la coincidencia simultánea o consecutiva, de diversos factores. En el caso de la crisis financiera actual, creemos que el crecimiento de la deuda bancaria, en forma de depósitos y en forma de emisiones de distintos tipos de activos financieros derivados, ha sido uno de los factores determinantes. Sin embargo dicho crecimiento, sería imposible si no se hubiera producido en la economía algún tipo de fenómeno real que arrastrara a la demanda agregada en una medida suficiente como para hacer que el mecanismo de creación de dinero bancario se pusiera en marcha de forma importante. En el caso español, se produjo una combinación de factores internos y de factores provenientes del exterior, es decir, debidos a la influencia de lo que sucedía en la economía internacional.

Respecto de la influencia exterior, fue la reducción de los tipos de interés que se promovió desde la Reserva Federal americana a principios del año 2001, influida seguramente por los atentados del $11 \mathrm{~S}$, el desencadenante inicial de los procesos posteriores de crecimiento del dinero bancario que están en el origen de la crisis. El Banco Central europeo, por su parte, haciendo frente a la desaceleración económica que se estaba viviendo a principios de los 2000, debido principalmente a una reducción de la inversión, y por la propia situación geopolítica, acompañó este movimiento con reducciones también de su tipo de interés de referencia. Estos movimientos fueron acompañados, en un entorno de crecimiento de la liquidez, con respuestas inmediatas de los tipos de interés interbancarios.

${ }^{7}$ Allais (1987), pág. 520. 


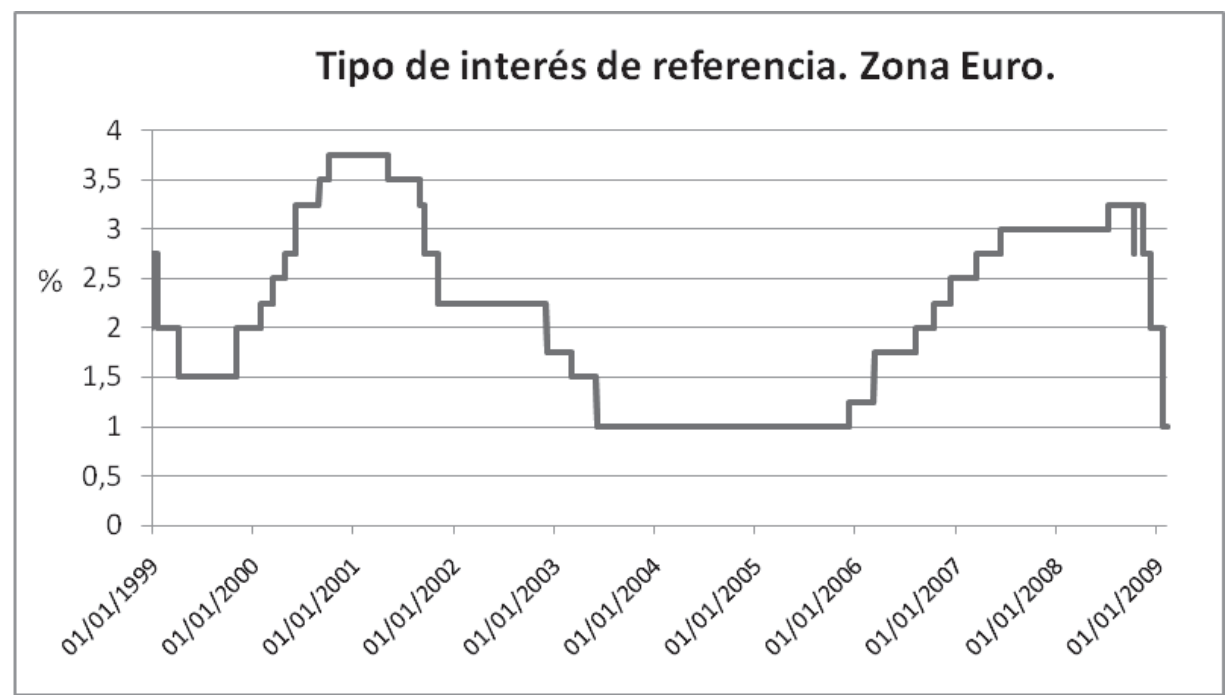

Fuente: Banco Central Europeo.

\section{Euribor a un año.}

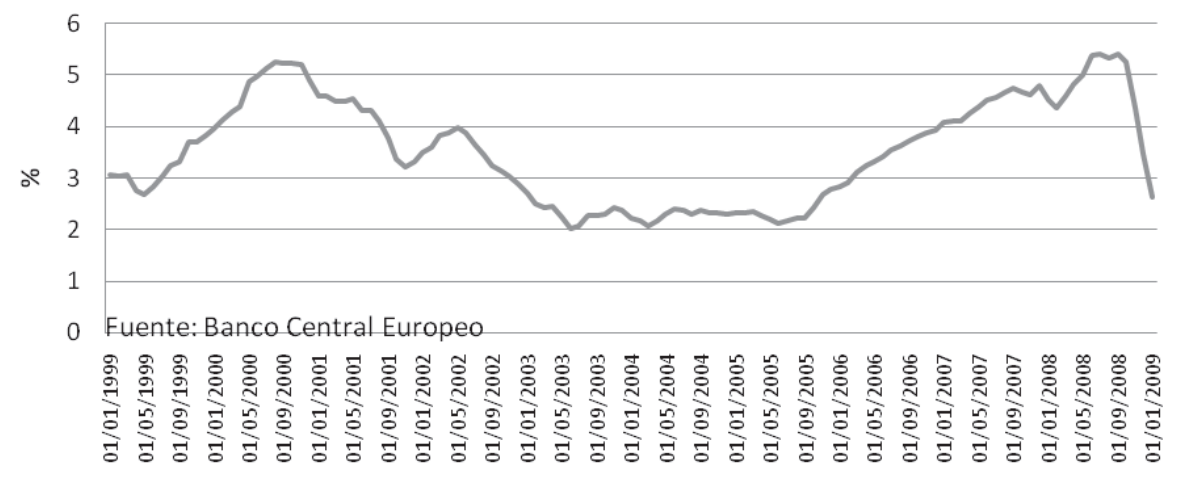

Fuente: Banco Central Europeo. 
En la zona euro, además, el objetivo de mantener la tasa de inflación cercana al $2 \%$, trajo consigo, en combinación con los bajos tipos de interés, el establecimiento de unas circunstancias muy favorables para el relanzamiento del endeudamiento tanto de las familias como de las empresas.

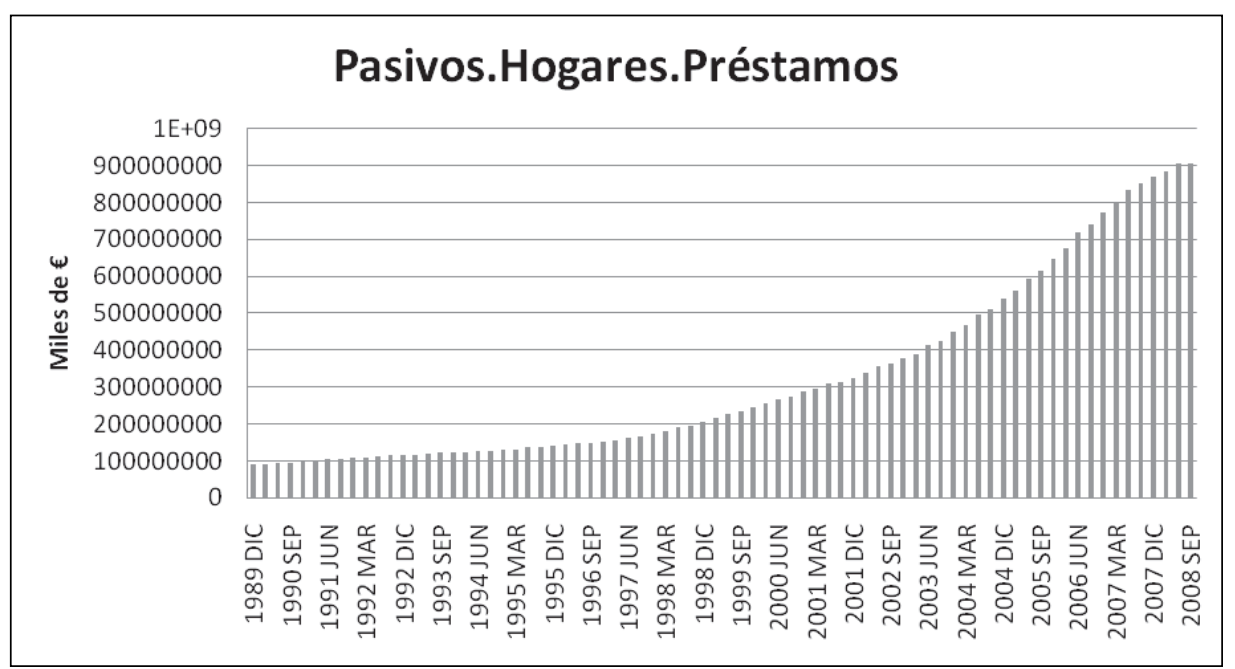

La reducción de los tipos de interés, además, coincidió con dos fenómenos muy relevantes desde punto de vista de la demanda interna y, ambos, relacionados con el tamaño de la población española: el primero, se refiere a los españoles que en los alrededores del año 2001 alcanzaron la edad media de matrimonio, cercana a los 30 años. Así, se puede observar en el gráfico que representa la pirámide de población española para el año 2002, como la población comprendida entre los 20 y los 35 años representaba en ese año cerca del $25 \%$ de la población española. 


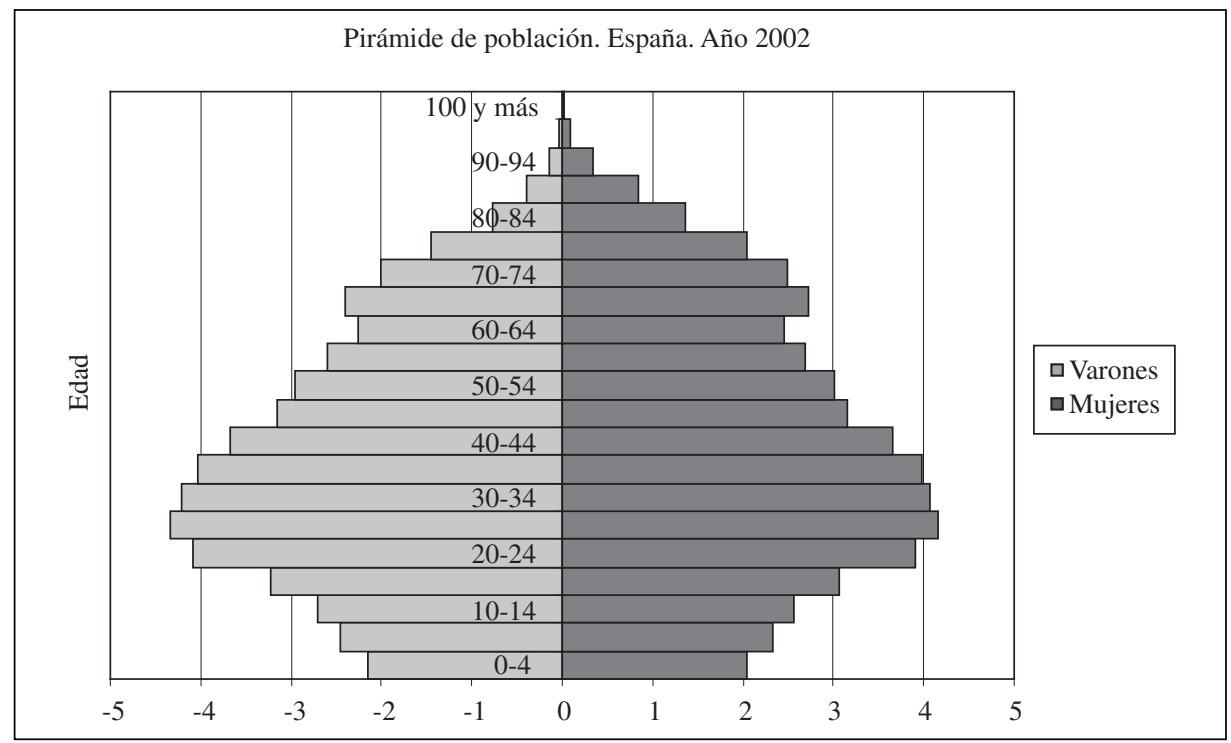

Fuente: Ministerio de Educación, Política social y Deporte.

El segundo fenómeno fue el del rapidísimo crecimiento de la población extranjera dentro debido a la inmigración. Esta población prácticamente se triplicó, pasando de 923.879 extranjeros en el año 2000 a 2.664.168 del año 2003. La reducción drástica de los tipos de interés coincidió con la llegada a la edad de independización de un volumen importante de la población española y, al mismo tiempo, con la llegada masiva de inmigrantes y, por lo tanto, con una necesidad creciente de vivienda en España.

Éstos hechos explicarían, a nuestro juicio, cuál fue el arranque inicial lugar de la economía real dónde comenzó el crecimiento de la demanda agregada. En efecto, la relación entre la evolución de la actividad en el sector inmobiliario y el ciclo económico, ha sido muy estudiada ${ }^{8}$. Es habitual que en estos trabajos se de categoría de «hecho estilizado» a la anticipación que tiene la evolución de la demanda de inmuebles (principalmente residenciales) respecto del PIB. Sin embargo, las relaciones entre actividad económica y vivienda son ciertamente complejas debido a los procesos de retroalimentación que se dan entre ambas. Hay que tener en cuenta que la vivienda no es sólo un bien de consumo duradero, sino también una inversión, y que, por lo tanto, su demanda

8 Véase Leung (2004), Leamer (2007) y Feldstein (2007). 
está condicionada por esta dualidad. La definición teórica de la influencia de los efectos de de riqueza, aparece por primera vez en la teoría de la renta permanente de Milton Friedman (1957) y Modigliani (1963), en la que estos ponían en relación la función de consumo de las economías domésticas con el ingreso o renta permanente (formada por el ingreso humano e ingreso o renta no humana —item en el que entraría precisamente la vivienda como parte de la riqueza de los agentes). En esta perspectiva, sería absolutamente normal que crecimientos en la riqueza personal de los agentes económicos debidos a aumentos en el precio de las viviendas, llevarán incrementos sucesivos de los niveles de consumo. Por otra parte, estos aumentos de la riqueza permiten también mayores niveles de endeudamiento.

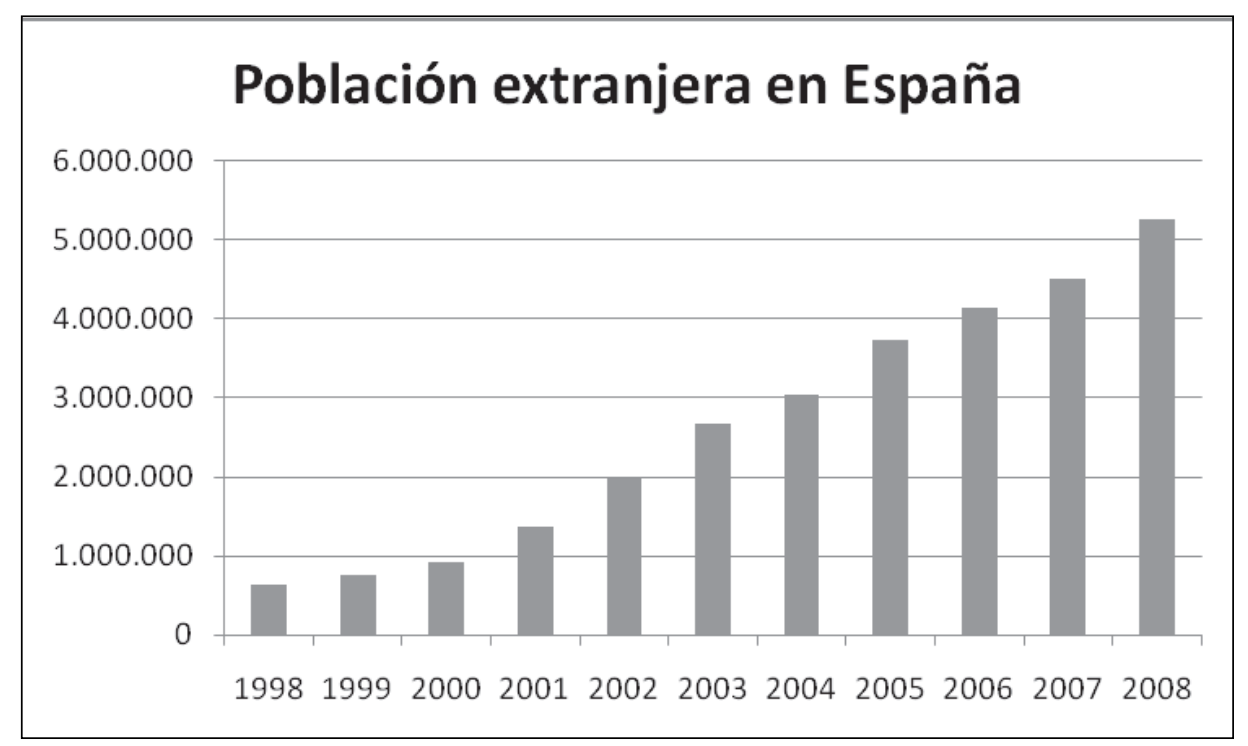

Fuente: INE.

De hecho, una de las fuentes de dificultad en el análisis de su influencia, depende de los poderosos efectos de riqueza que se producen cuando la economía vive fuertes aumentos de precios de las viviendas lo que, por otra parte, sólo podría suceder bajo determinadas condiciones muy especiales (entre las que no es nada desdeñable contar con el propio motor económico que pone en marcha el sector inmobiliario). La evidencia empírica de esta relación común y de las dificultades que introduce en su análisis, ya fue tratada por Matsuyama (1990). En este sentido, parece obvio que esta 
interrelación se ve multiplicada porque el sector inmobiliario arrastra tras de sí una cantidad de actividad económica indirecta muy importante. Las casas no sólo hay que construirlas con un gran uso de mano de obra y material, que involucra el uso masivo de acero y cemento, sino que una vez construidas hay que llenarlas de bienes de línea blanca y marrón.

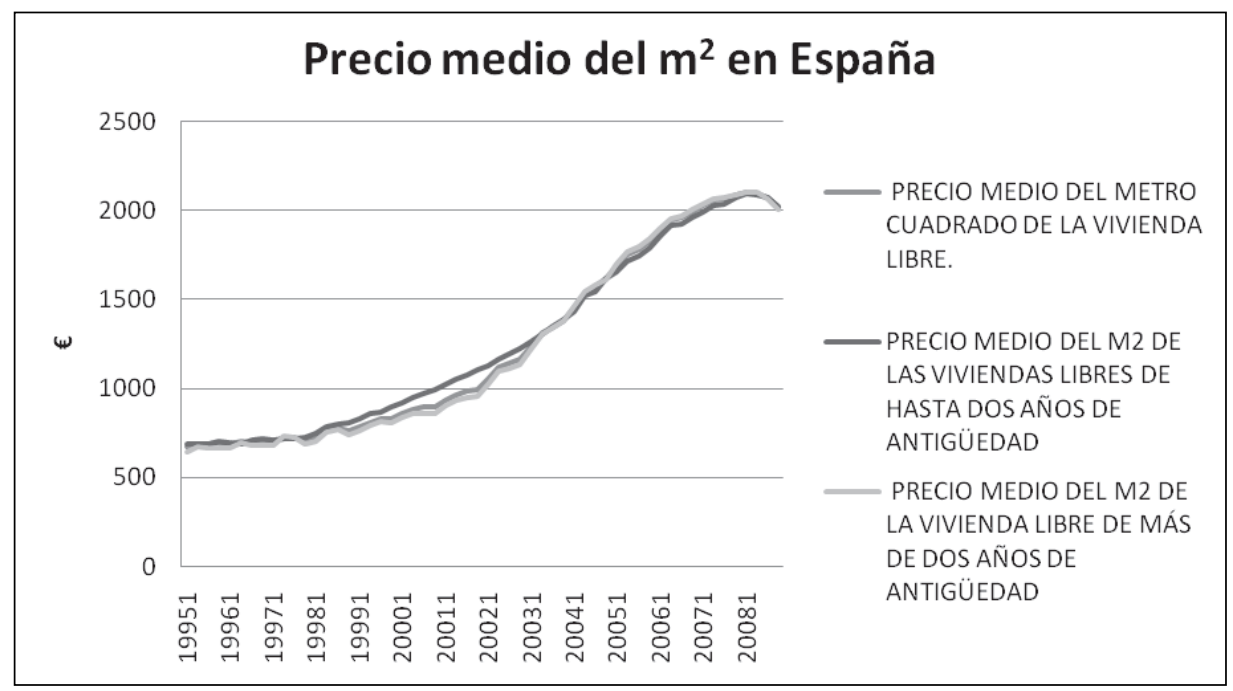

Fuente: Ministerio de la Vivienda.

En España, y desde mediados de los años 90, el crecimiento de los precios de los inmuebles ha sido constante y muy acelerado, ya sean medidos estos precios en términos reales, en términos monetarios, resaltando la magnitud de la subida así como su duración, de aproximadamente 10 años (que dura hasta mediados del año 2007). Como factor coadyuvante, el crecimiento de la demanda de viviendas se encontraría muy pronto con la tradicional escasez de terreno de la economía española, que se debe en gran medida, a la gestión que realizan los Ayuntamientos del mismo. De tal manera, que en España se da la paradójica situación de tener una baja densidad demográfica ( 8,8 personas por kilómetro cuadrado) y carestía del suelo.

En cualquier caso, la revalorización de las viviendas ha sido un factor que ha aumentado el colateral con el que las familias podían respaldar nuevos endeudamientos, o bien aumentando su gasto en consumo, o bien reduciendo su ahorro en la confianza de que podrían endeudarse fácilmente más adelante. Esto hizo que los pasivos de los hogares representarán el $83 \%$ de su renta bruta disponible en 2002 y más del 100\% ya en el año 
2004. Endeudamiento inusual en la economía española y que tuvo que ser sostenido, en una medida nada despreciable, por el recurso a la financiación extranjera, lo que disparó el déficit exterior español a cifras nunca conocidas antes y que, en el último trimestre de 2008, ya alcanzaba el $160 \%$ del PIB.

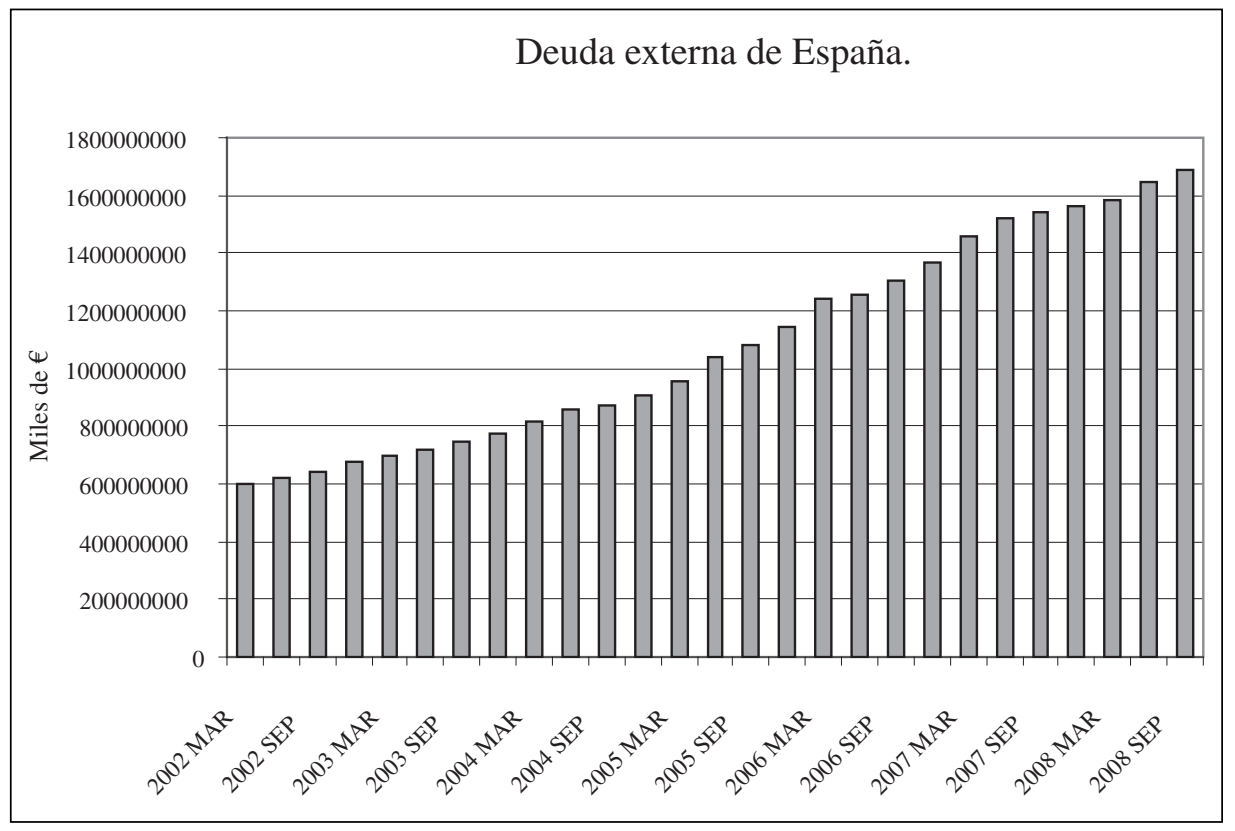

Fuente: Banco de España.

\section{TERCERA CONDICIÓN DE POSIBILIDAD:}

\section{EL CRECIMIENTO DE LA DEUDA BANCARIA A CORTO PLAZO}

El despegue de la economía española ha estado favorecido por la capacidad de generar dinero bancario, lo cual se ha visto especialmente reflejado en la evolución de la M3 en España en comparación con su crecimiento en la zona euro. Esta capacidad de generar depósitos se concentra, especialmente, durante el año 2000 y desde mediados del 2005 hasta el rompimiento de la burbuja inmobiliaria norteamericana a mediados de 2007. 


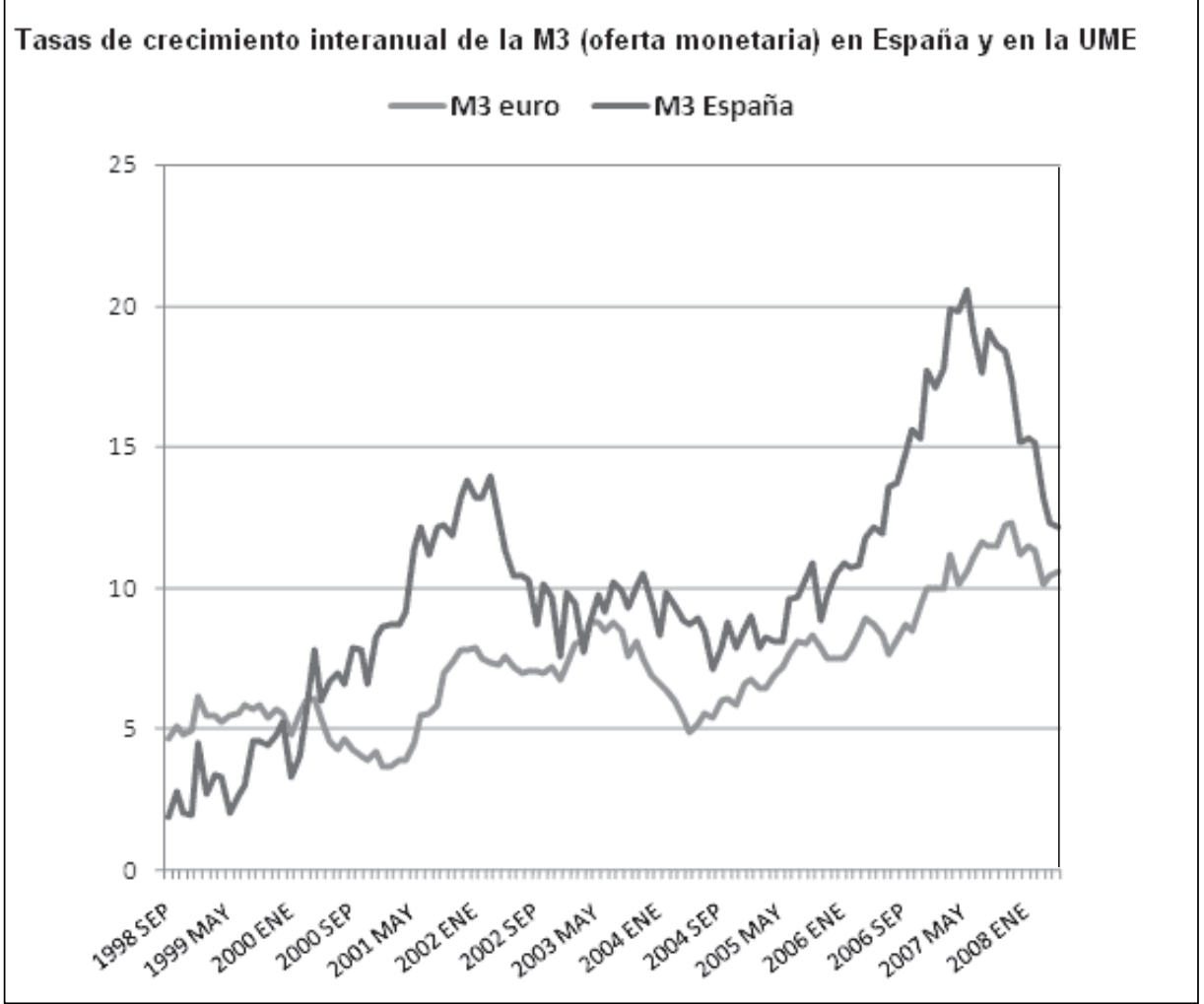

Fuente: Banco Central Europeo y Banco de España.

Sin embargo, esta no ha sido la única fuente de generación de deuda a corto plazo de la banca española, sino que los procesos internacionales de creación de derivados crediticios y apalancamiento financiero, han tenido también en España un terreno propicio para su crecimiento.

En los últimos quince años, los bancos comerciales de todo el mundo han ido abandonando su papel tradicional de prestamistas para ir desempeñando, cada vez en mayor grado, la función de transformar y comerciar con el propio riesgo crediticio. En gran medida, este cambio de tipo de negocio se ha visto favorecido por la gran competencia existente dentro del sector bancario, que ha tendido a reducir los márgenes de la intermediación financiera. De hecho, algunos autores apuntan cómo el mercado de préstamos se ha convertido en un vehículo para atraer a los clientes hacia otros tipos de productos. Entre éstos, tienen una importancia fundamental los derivados crediti- 
$\operatorname{cios}^{9}$, los activos sintéticos y, en general, todos aquellos instrumentos financieros que permiten convertir la exposición al riesgo en una mercancía vendible, ya sea de forma individual o colectiva.

Algunos factores objetivos han favorecido el rápido crecimiento de su contratación: los procesos de internacionalización y progresiva desregulación de las actividades financieras y bancarias; la discrepancia observada entre el manejo del riesgo de mercado y el crediticio en mercados muy sofisticados (como los de interés o de tipos de cambio); los avances en las tecnologías de la información y la encriptación de datos; una mayor exigencia de eficiencia en la gestión del capital en el sector bancario; el hecho de que las operaciones con estos derivados crediticios están fuera del balance, y no hay necesidad de respaldarlas con capital (con la consiguiente liberación de recursos para préstamos adicionales), etc. La especialización en la estructuración y transformación del riesgo, ha permitido, además, la creación de productos financieros a la carta que son más fáciles de vender en los mercados, en comparación con otros activos financieros de características iguales para todo el mundo. De esta forma, y como señalan Bruyère et alia (2006), los bancos han podido adaptarse a las peticiones directas de los inversores, tomando como recurso material primario el propio riesgo crediticio y alterando las características tanto de riesgo como de rentabilidad de los mismos (incluso por medio de la subcontratación de entidades especializadas en la gestión de riesgos).

En España, la transformación de los derechos de crédito presentes y derechos de cobro futuros en activos que puedan negociarse en mercados secundarios, se denomina titulación. Esta operación puede materializarse por dos vías diferentes: a través de un fondo de titulación sin personalidad jurídica, generalmente manejado por una sociedad de gestión; o bien a través de la constitución de una sociedad especial denominada Special Purpose Vehicle, un tipo especial de sociedades que se crean para algún tipo de fin muy concreto (como es el caso de la titulación de préstamos, por ejemplo). En España y Francia los fondos titulizados se gestionan bajo la primera de las alternativas, exclusivamente.

Estos fondos de titulación agrupan diversos tipos de activos de diferentes características (referidas a plazo, rentabilidad y riesgo) y emiten títulos referidos a dicho pool. En concreto, los títulos que puede emitir el fondo son principalmente bonos de titulación, que están sujetos a calificación.

9 Un derivado crediticio es un activo financiero con el que se fija un precio con el que comerciar el riesgo crediticio de un determinado activo subyacente, independientemente de otros riesgos que pueda implicar, por ejemplo el de mercado. 


\begin{tabular}{|c|c|c|c|c|c|c|}
\hline & 2002 & 2003 & 2004 & 2005 & 2006 & 2007 \\
\hline Total bonos de titulización emitidos & 18.803 & 36.740 & 50.525 & 69.044 & 91.608 & 141.627 \\
\hline Mediante FTH (a) & 6.776 & 5.030 & 4.890 & 6.850 & 4.300 & 4.740 \\
\hline Mediante FTA & 12.027 & 31.710 & 45.635 & 62.194 & 87.308 & 136.887 \\
\hline Préstamos hipotecarios (b) & 4.247 & 11.828 & 13.967 & 22.314 & 34.663 & 57.550 \\
\hline Cédulas hipotecarias (c) & 3.500 & 10.650 & 18.685 & 24.280 & 25.670 & 26.655 \\
\hline Préstamos a promotores (d) & 320 & 0 & 475 & 730 & 0 & 0 \\
\hline Subtotal hipotecario $(a+b+c+d)$ & 14.843 & 27.508 & 38.017 & 54.175 & 64.633 & 88.945 \\
\hline FTPYME ${ }^{1}$ & 2.713 & 5.303 & 8.964 & 2.944 & 7.956 & 6.474 \\
\hline FTGENCAT $^{1}$ & 397 & 950 & 0 & 2.177 & 1.860 & 2.020 \\
\hline Resto PYMES ${ }^{1}$ & 0 & 0 & 0 & 1.250 & 2.979 & 2.485 \\
\hline Préstamos a empresas ${ }^{2}$ & 0 & 0 & 0 & 3.100 & 5.536 & 19.250 \\
\hline Subtotal PYMES y Empresas & 3.110 & 6.253 & 8.964 & 9.471 & 18.331 & 30.230 \\
\hline Préstamos a grandes empresas ${ }^{3}$ & 0 & 0 & 0 & 556 & 0 & 0 \\
\hline Cédulas territoriales & 0 & 1.400 & 0 & 665 & 0 & 0 \\
\hline Bonos de tesorería & 0 & 0 & 0 & 1.180 & 1.450 & 0 \\
\hline Créditos AAPP & 0 & 0 & 1.850 & 0 & 0 & 0 \\
\hline Préstamos consumo & 0 & 1.280 & 235 & 0 & 5.527 & 3.592 \\
\hline Préstamos auto & 850 & 0 & 1.000 & 2.598 & 1.360 & 2.840 \\
\hline Arrendamiento financiero & 0 & 0 & 0 & 0 & 0 & 2.500 \\
\hline Otros créditos ${ }^{4}$ & 0 & 300 & 458 & 400 & 307 & 13.521 \\
\hline Total pagarés de titulización emitidos ${ }^{5}$ & 6.114 & 3.870 & 3.724 & 2.767 & 1.993 & 465 \\
\hline Total bonos más pagarés & 24.917 & 40.610 & 54.248 & 71.811 & 93.600 & 142.092 \\
\hline
\end{tabular}

Fuente: CNMV.

El crecimiento de este mercado en nuestro país ha sido muy importante debido, fundamentalmente, a que los bancos comerciales no eran capaces de captar tantos fondos como eran necesarios para hacer frente a su creciente inversión en créditos hipotecarios, lo que hacía necesaria la captación de nuevos fondos (ya fuera vendiendo activos, endeudándose o emitiendo capital). En concreto, el volumen negociado a partir del año 2000 ha sido muy relevante, situándose en el entorno del 13\% del total negociado en toda Europa (siendo el Reino Unido, como plaza financiera internacional, el líder del mercado europeo con una cuota cercana al 40\%).

Los fondos titulizados pueden tener orígenes en créditos o subyacentes diversos (al consumo, automóvil, recibos de tarjetas de crédito, etc.) pero su fuente principal son los préstamos hipotecarios (entre el 63 y el 78\%).

Sin embargo, la mayor parte de este tipo de nuevos activos financieros se sustenta en el riesgo crediticio de los préstamos hipotecarios realizados por los bancos comerciales. Es 
decir, el funcionamiento de los bancos comerciales en los últimos años ha intentado llevar un paso más allá el arbitraje de tipos de interés al que están habituados. De tal manera, que la captación de recursos a corto plazo (y, por tanto, su volumen de endeudamiento a corto plazo) ha aumentado de manera exponencial y muy por encima del crecimiento también exponencial de su préstamos a largo plazo en el mercado hipotecario. En nuestra opinión, esto ha de llevar necesariamente a una incompatibilidad por desproporción entre el crecimiento de la cantidad de deuda a corto plazo, representada por el crecimiento de depósitos y el crecimiento de los derivados crediticios. El crecimiento de esta desproporción está en relación con las operaciones que están destinadas a mantener la devolución de la deuda a corto plazo, por la insuficiencia de la recuperación de rentas a largo plazo provenientes de los préstamos hipotecarios para realizar esta labor. Cada operación añade una cuantía cada vez mayor a la deuda a corto plazo, de manera que la desproporción entre las necesidades de liquidez para las operaciones corrientes y el crecimiento de esa deuda, es lo que, a la postre, produciría la crisis de liquidez del banco y la contracción crediticia. Esta crisis ha sido adelantada por un proceso paralelo, del cuál el caso español ha sido un reflejo, en la economía de los Estados Unidos, ya que las necesidades de financiación interna ni siquiera se veían cubiertas por la captación de fondos del sector financiero nacional y se debía recurrir al internacional de manera creciente.

\section{CONCLUSIÓN}

A pesar de que las crisis financieras tienen un impacto importantísimo sobre el crecimiento económico de las naciones, han sido relativamente poco estudiadas por la teoría económica contemporánea, más preocupada por los impactos que tienen sobre el ciclo los choques exógenos de tipo real. Sin embargo, debido a la propia configuración del sistema financiero, sustentado por la emisión de dinero fiduciario y por la existencia de la reserva fraccionaria, está siempre en peligro de producir reducciones artificiales de los tipos de interés que permitan un desplazamiento masivo de las inversiones productivas hacia sectores que, a la larga, no serán capaces de producir un retorno de las mismas suficiente como para evitar el advenimiento de la crisis. Se demuestra así, una vez más en la historia económica, cómo el crecimiento sostenido sobre volúmenes enormes de deuda, es un gigante con los pies de barro, que es derribado en cuanto las expectativas de beneficio se encuentran con los primeros síntomas de agotamiento en la producción de deuda a corto plazo.

En España, los riesgos de esta vía de crecimiento económico parecían vinculados más a lo ocurrido en el exterior que a la posibilidad de un riesgo endógeno. Pero no es 
cierto. El volumen de deuda sobre el que se ha sustentado nuestro crecimiento reciente, sigue siendo una amenaza para el crecimiento económico futuro. En España se dibuja un escenario de gran peligro y complejidad por la coincidencia de las circunstancias más adversas. Probablemente, el enorme volumen de deuda a corto plazo no ha mostrado aún todos los problemas de liquidez que implica para las instituciones financieras, un parón muy violento de la actividad económica que amenaza con elevar enormemente los niveles de desempleo, una deuda externa de dimensiones enormes y unos márgenes de maniobra para la política económica muy limitados por la pertenencia a la zona euro, la naturaleza de las medidas de política económica a aplicar, que son tendentes a retardar los efectos de la crisis, no a solucionarlos.

Una vez desatada la restricción del crédito, la devolución de la deuda a corto plazo se convierte en una misión de muy difícil cumplimiento. Las dificultades de los bancos comerciales, no obstante, se convierten de problema privado en problema público porque nadie en su sano juicio permitiría un colapso del sistema financiero. En este contexto, y lamentablemente, las soluciones aportadas desde las instituciones públicas orientadas a sanear las cuentas de las instituciones financieras privadas y a incrementar el gasto, producirán efectos contrarios a los deseados en el medio plazo. Por un parte, no permitirán un reajuste de las inversiones desde el sector privado, y, por lo visto hasta ahora, reincidirán en mantener vivos los sectores que no son ya rentables. Por otra, amenazan con producir procesos inflacionarios de gran importancia en un futuro próximo tras un período en el que la economía rozará, o incluso puede entrar, en deflación por la reducción de la demanda. Es por ello que la perspectiva de una recesión prolongada no puede descartarse.

\section{REFERENCIAS BIBLIOGRÁFICAS}

Allais, M. (1984), «The Credit Mechanism and its Implications», en G. R. Feiwel (1987) (ed.), Arrow and the Foundation of the Theory of Economic Policy, Nueva York, New York University Press.

Bank for International Settlements (2008), 78th Annual Report, Basilea.

BruYÈre, R. y cols. (2006), Credit Derivatives and Structured Credit A Guide for Investors, West Sussex, John Wiley and sons.

Comisión Nacional del Mercado de Valores (2007), Informe Anual, Madrid.

DufFIE, D. (2008), «Innovations in credit risk transfer: implications for financial stability», $B I S$ Working Papers, núm. 255. 
Ebeling, R. M. (1990), Money, Method and the Market Process: Essays by Ludwig von Mises, Dordtrecht, Kluwer Academic Publishers.

Feldstein, M. S. (2007), «Housing, Credit Markets and the Business Cycle», NBER Working Paper núm. 13471.

Huerta de Soto, J. (1998), Dinero, crédito bancario y ciclos económicos, Madrid. Unión Editorial.

Leamer, E. E. (2007), «Housing IS the Business Cycle», NBER Working Paper núm. 13428.

Leung, C. (2004), «Macroeconomics and Housing», Journal of Housing Economics vol. 13, núm. 4.

Machlup, F. (1967), Semántica Económica, México, Siglo XXI.

Martínez Pagés, J. y Maza, L. A. (2003), «Análisis del Precio de la Vivienda en España», Documento de Trabajo núm. 0307, Banco de España.

Phillips, J. (1995), The Chicago Plan \& New Deal Banking Reform, Nueva York, M. E. Sharpe, Armouk.

Samuelson y Nordhaus (1993), Economía, 14. a edición, Madrid, McGraw-Hill.

Securities Industry and Financial Markets Association (2008), Nueva York, Research Report. 